\title{
An Evaluation of Training Needs of Supervisors of South African Chemical Weeding Plantation Forest Operations through Forester Perceptions
}

\author{
Trymore Chivinge and Hlomla Dali \\ Department of Forestry and Natural Resources Management, Fort Cox College of Agriculture and Forestry, P.O. Box 2187, King \\ William's Town 5600, Eastern Cape, South Africa
}

\begin{abstract}
The success of an annual plan of operations (APO) for a plantation forest management unit (FMU) has great reliance on the capacity of field supervisors who execute it with workers. Foresters' perception of skills and performance levels of field supervisors in charge of chemical weeding operations, which are keys to integrated vegetation management strategies at FMUs, were evaluated through a researcher-administered questionnaire implemented through telephone interviews. The research focussed on chemical weeding, of which implementation quality impacts directly on operational costs, worker safety, negative environmental externalities and crop performance. The study was done to establish capacitation requirements (training needs) for the plantation forest sector in the Eastern Cape, Western Cape and KwaZulu-Natal provinces of South Africa. The results of the research identified skills gaps and emotional issues that could be addressed through training. Overall, chemical weeding field supervisors (CWFS) were adequately prepared to perform in most key result areas of planning and leadership. They, however, faced considerable challenges in functions related to controlling and organizing work. In all three provinces, the highest levels of performance inadequacy were in safety and team discipline. Some province-associated peculiarities in field supervisor performances were also identified. Remedial action that foresters recommended was related mostly to the need to strengthen technical and workplace culture management skills. It was observed that effective skills development in CWFS would require planned continuous improvement programmes.
\end{abstract}

Key words: Worker skills, training needs, vegetation management.

\section{Introduction}

Vegetation management, or more generally weeding, is a predominant tending operation on silvicultural annual plan of operations (APO) that reduces the negative impacts of undesirable plants in forests [1]. Weeding is critical, particularly during establishment prior to crown closure, since it accelerates early site capture and enhances forest site productivity [2]. Traditionally, an APO, i.e., annual programmed work at the forest management unit (FMU) level, is developed based on information from a forest planning database and complimentary forest inventory or field checks. APO targets that are set for

Corresponding author: Trymore Chivinge, M.Sc., research fields: forest resource assessment and forest management capacitation. individual silvicultural activities include budgeted quantities of work that is scheduled to be done at particular work sites (compartments), in specified time periods and using desirable input levels per hectare for labour, machinery and chemicals. Time horizons for APO may be arbitrarily set to coincide with the organisation's financial reporting year or normal calendar year [3]. The prescription of particular activities in the year is done taking into account the influence of seasonal weather conditions.

South Africa has about 1.2 million ha of commercial planted forests [4] that are increasingly under intensive forest management $[5,6]$. Critical to the implementation of intensive silvicultural APO is the capacity of field supervisors [7] to manage inputs and enhance their efficient application in each of a variety of operations on a day-to-day basis, as they 
oversee worker teams.

With rising labour costs, chemical weeding has become an essential part of efficient vegetation management strategies, on which successful silvicultural APO implementation is premised. However, there has been growing international pressure for drastic reductions in herbicide use since the early 1990s. From weed control and thus silvicultural perspectives, there are also growing concerns of an escalating risk of herbicide resistance in targeted weed species [8]. The forest sector has also been forced to be responsive to environmental forest certification standards' specific encouragement for diminished use of herbicides, while encouraging the increased use of integrated vegetation management options [9]. Despite this pressure, however, herbicide use in plantation forests remains preeminent due to its cost-effectiveness [10]. The use of herbicides also enables implementation of massive establishment programmes, as is necessary in post-fire damage situations of the scale that was witnessed in 2003 in South Africa [11], since the requirements of large area plantings outstrip the efficacy of programming weeding APO on the basis of cultural, manual and mechanical methods alone. Additionally, vegetation that has underground stems will more likely require a systemic herbicide to obviate repeated weeding operations within one year, thus, allowing the forester to minimise stand establishment costs. The use of herbicides in vegetation management also offers the forester opportunities for cost minimisation outside stands, e.g., in alien species control [12] and fire tracer belt preparation.

In current commercial forest sector circumstances, which make it inevitable to use chemicals, special contractor and own labour teams are developed and capacitated to ensure the success of APO implementation. Acceptable worker safety [13] and environmental protection are critical responsibilities for field supervisors. Most commercial plantation forests owned by corporate firms are subject to recurring Forest Stewardship Council (FSC) forest certification audits. For this reason, foresters rely on field supervisors to uphold prescribed best practice. The need to develop and monitor worker skills in silvicultural operations so as to sustain the requisite high operational standards is acknowledged [14]. This need is more critical where silvicultural operations have progressively been outsourced to contractors. More recently, the drive to modernise traditionally manual silvicultural operations through mechanisation has stimulated an urgency to ensure that labour, especially field supervisors, are appropriately skilled. In proactive commentary, Steenkamp [15] has urged appropriate strengthening of vocational curricula in order to meet this dynamic.

The quality of supervision in forest operations is critical in that it ensures efficiency and effectiveness in running the FMU [16]. Continuous appraisal of supervisory skills levels in operational team leaders is therefore necessary in order for foresters to programme appropriate proactive interventions (frequently vocational training) that are designed to support operational efficiency and effectiveness in task outcomes [17].

Levels of labour productivity and consequentially profitability are cardinal parameters in commercial plantation forest management [18]; field supervisors have pivotal contribution. Essentially, the field supervisor performs line management functions of the first order. In the purview of a supervisor's duties, four distinct skills or key performance areas are identifiable from five managerial functions suggested by Koontz [19], i.e., planning, leading, organizing and controlling (Table 1). In the current study, it was considered that the extent of company-dependent variability in the field supervisor's input in staffing (or electing members to their team) would not be easy to ascertain. Contemporary foresters commonly prescribe, in operational manuals, desirable action that field supervisors are required to ensure. Significant deviations from prescription are treated as procedural 
non-conformances. To effectively and efficiently achieve acceptable team performance, specific supervisory duties have to be done. Common practice is for foresters to experientially evaluate field supervisor performance, build a perception of requisite training needs and nominate their subordinates for skills upgrading courses offered by herbicide suppliers or registered vocational training service providers.

Broad requisite skills for a chemical-weeding field supervisor may be categorized as: (1) technical (i.e., task-related), in which task performance is enhanced, e.g., by knowledge of chemical handling and plant biology, (2) conceptual (i.e., strategic), in which case good supervisor attributes include the ability to relate team outputs to overall objectives of the FMU, (3) human relations skills (i.e., "soft" skills), which espouse the cultural setting of the workplace, and (4) decision-making skills, which relate to the rationale of judgement, by which tasks are carried-out in as far as concern for results is mirrored.

Commercial plantation forest sector stakeholders require clear indications on sectorial training needs for purposes of strategic planning and operational management, including the appropriate identification of interventions in traditional on-the-job coaching [20]. Thus, this paper attempted to assess regional training needs in chemical weeding field supervisors (CWFS) through analysis of foresters' perception of ranked competencies in CWFS under their control in three of South African provinces which have significant commercial plantation forests.

\section{Materials and Methods}

\subsection{Study Site}

Three contiguous South African provinces with significant commercial plantation forests were considered for the study, i.e., KwaZulu-Natal (KZN), Eastern Cape (EC) and Western Cape (WC). All three provinces lie North to South (KZN, EC and WC, respectively) along the Indian Ocean, forming the
Eastern edge of mainland South Africa (Fig. 1).

Forestry firms ordinarily recruit labour from local sources, and considerable influences on workplace culture are to be expected from regional ethnicity of the majority of workers.

\subsection{Procedure}

On the basis of traditional management functions (Table 1) [19], generic elements of supervisory performance were solicited from a second year diploma in forestry student focus group.

The identified elements were used as criteria for assessing supervisory performance of commercial plantation forest field supervisors as perceived by foresters who supervised their work on a daily basis. The foresters were asked to elect appropriate remedial action from limited choices offered on a researcher-administered questionnaire. Table 2 presents the main elements of the data collection instrument used. The categorical relationships between traditional management functions, perceived supervisory performance and recommended remedial action, as perceived by respondents, are set-out. The interpretation of performance which would "need improvement" was that such performance was perceived as "inadequate".

The researcher-administered questionnaire survey was conducted using mobile telephone-to-mobile telephone contact. Snowball sampling was employed. Initially, one silviculture forester's mobile contact number was identified in each province based on the researchers' background knowledge. From the first telephone interview, in each case, the forester was asked to supply a maximum of two mobile telephone numbers, on which fellow forester(s) who were in-charge of silviculture were contactable. The process was repeated for each subsequent telephone interview.

A total of 60 telephone interviews were conducted over 5 d, with 20 interviews in each province. Forty-five valid (complete) interviews out of 60 (i.e., $75 \%$ ) were considered for analysis. 


\subsection{Data Analysis}

Post hoc analysis of the questionnaire responses was performed using Tuckey's honestly significant difference (HSD) test in order to ascertain differences between treatment means as advised by Durrheim [21]. The SPSS statistical package was used in the analysis [22].

\section{Results}

Of the valid data set, there were generally older male foresters than female foresters (Fig. 2). There, however, were no significant differences in age classes and gender of respondents, at the 95\% confidence level, within and between provinces.

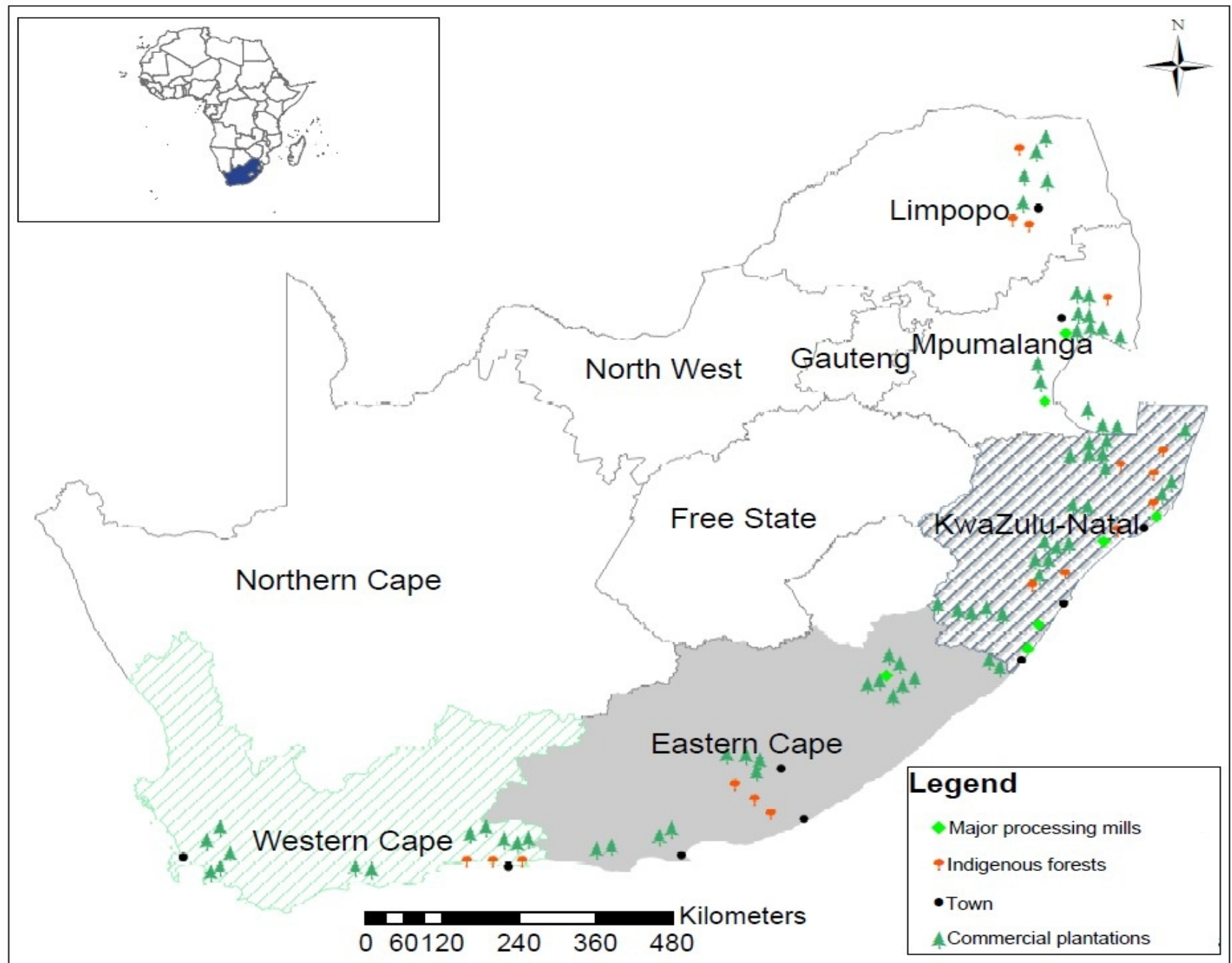

Fig. 1 Geographical position of South Africa and location of plantation forest-bearing provinces in which CWFS performance was evaluated.

Table 1 Categories of line management roles of field supervisors.

\begin{tabular}{ll}
\hline Supervisory function & Supervisory performance criteria \\
\hline 1. Planning & Setting targets and identifying means to achieve them \\
2. Organizing & Designing and allocating roles to team members \\
3. Staffing & Selecting, appraising and developing team members \\
4. Leading & Motivating and enriching team output \\
5. Controlling & Measuring progress and redressing activities \\
\hline
\end{tabular}

Data according to Koontz [19]. 
Table 2 Data collection instrument for soliciting performance perceptions of CWFS and forester-recommended interventions.

\begin{tabular}{|c|c|c|c|c|}
\hline \multirow{2}{*}{$\begin{array}{l}\text { Supervisor operational } \\
\text { skills area }\end{array}$} & \multirow{2}{*}{ Activity area } & \multicolumn{2}{|c|}{ Performance rating } & \multirow{2}{*}{$\begin{array}{l}\text { Recommended intervention(s) on } \\
\text { skills area }\end{array}$} \\
\hline & & $\begin{array}{l}\text { Needs } \\
\text { improvement }\end{array}$ & Adequate & \\
\hline \multirow{4}{*}{ Planning } & Resource mobilization to field & & & No action \\
\hline & Infield work organization & & & Work culture counselling/training \\
\hline & Scheduling resources & & & Technical training \\
\hline & Timing of treatments & & & Personnel change \\
\hline \multirow{4}{*}{ Leading } & Work demonstration & & & No action \\
\hline & Target-setting & & & Work culture counselling/training \\
\hline & Motivating team & & & Technical training \\
\hline & Developing subordinates & & & Personnel change \\
\hline \multirow{4}{*}{ Organizing } & Activating team & & & No action \\
\hline & Safety management & & & Work culture counselling/training \\
\hline & Methodology choice & & & Technical training \\
\hline & Allocating team roles & & & Personnel change \\
\hline \multirow{4}{*}{ Controlling } & Cost control: resource application & & & No action \\
\hline & Record keeping & & & Work culture counselling/training \\
\hline & Team discipline & & & Technical training \\
\hline & Work tempo & & & Personnel change \\
\hline
\end{tabular}

\subsection{Planning}

Fig. 3 presents the patterns in rated planning performance attributes of CWFS. The level of scheduling (programming), timing (real-time optimization) and infield organization (layout) of work/tasks was perceived to be of an acceptable level in CWFS in all provinces.

There was general contestation of perceptions on the adequacy of planning skills in CWFS, but in the Eastern Cape, foresters were in agreement $(P<0.05)$ that CWFS were generally unsatisfactory in resource mobilization, i.e., deploying teams, equipment and materials to the worksite.

\subsection{Leading}

Foresters' perceptual ratings of performance by CWFS in their leadership duties are presented in Fig. 4. Considerable CWFS performance variability was observed in key performance areas within the functional role of leading. This equivocal tendency in responses on this parameter possibly indicated that leadership performance was influenced more by attributes endogenous to organizations rather than regional norms that may relate to ethnicity.

A number of results that are significant at the $95 \%$ confidence level are illustrated in Fig. 4. In the Eastern Cape, setting of work targets, demonstrating work procedures/techniques to team members and developing subordinates by CWFS were perceived to be inadequate. Elsewhere, CWFS in KwaZulu-Natal were significantly $(P<0.05)$ perceived to be poor at motivating subordinates.

\subsection{Organizing}

Skills for organizing teams, in particular, activating team members for task performance, was judged to be significantly inadequate $(P<0.05)$ in CWFS in all provinces (EC, WC and KZN). Fig. 5 illustrates these findings.

CWFS in all provinces were perceived to be significantly $(P<0.05)$ inadequate in managing safety; all respondents were unanimous on this aspect. However, allocating tasks to subordinates and electing appropriate work methods were perceived to be adequate in CWFS in all provinces. 

Plantation Forest Operations through Forester Perceptions

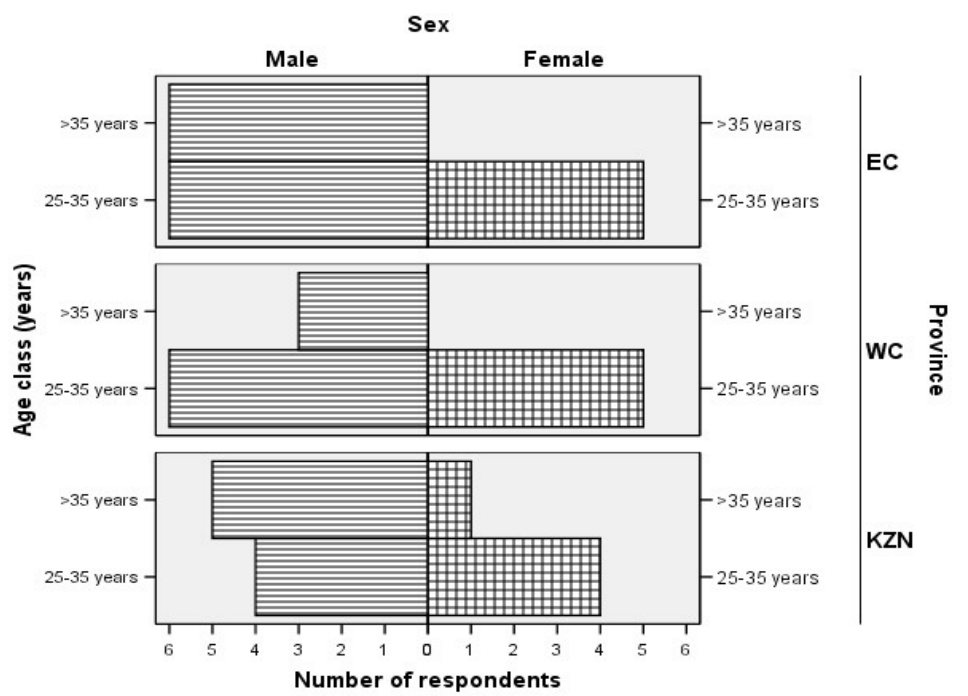

(a)

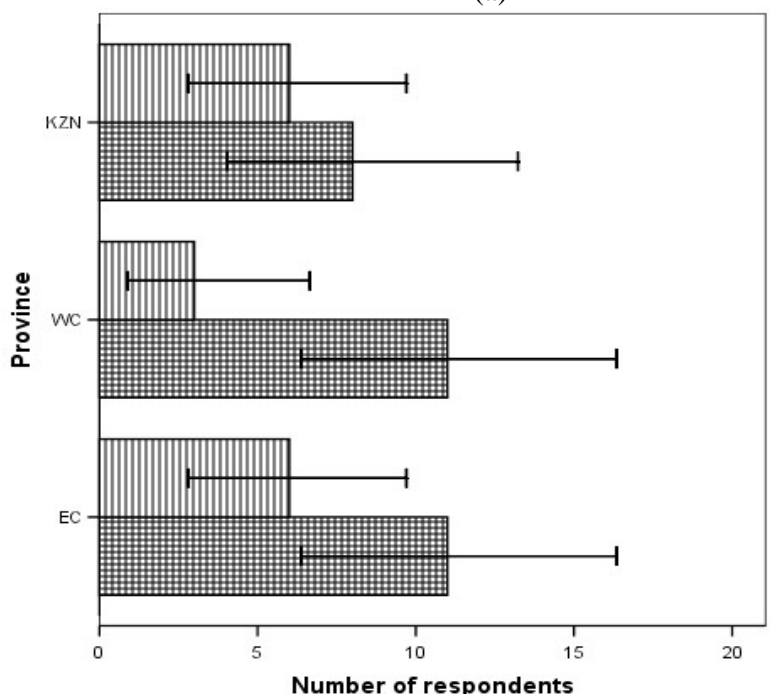

Age class (years)

㖆 25-35 years

而 $>35$ years

(b)

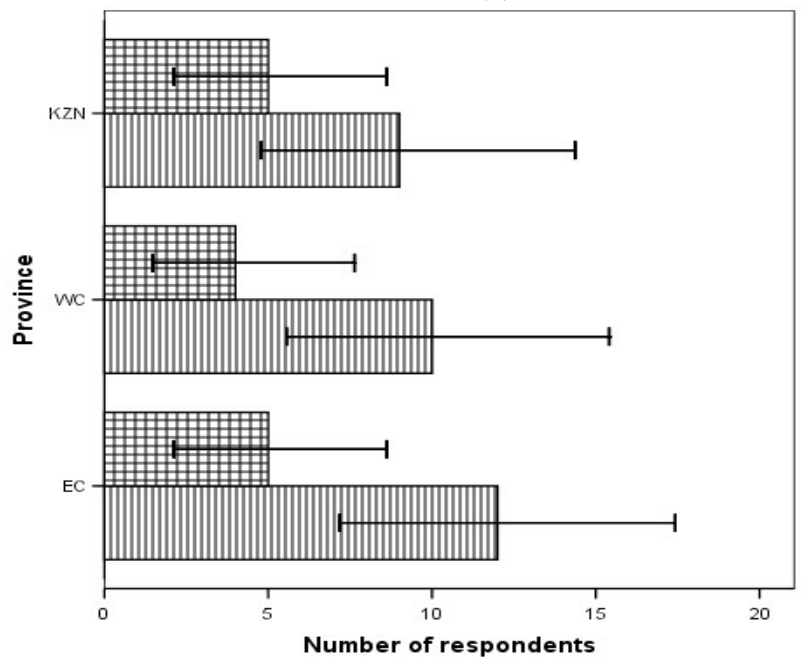

Sex

盂 Male

再Female

(c)

Fig. 2 Demography of foresters interviewed for the study in EC, WC and KZN provinces.

EC: Eastern Cape, WC: Western Cape, KZN: KwaZulu-Natal. Error bars show 95\% confidence interval. 

Plantation Forest Operations through Forester Perceptions

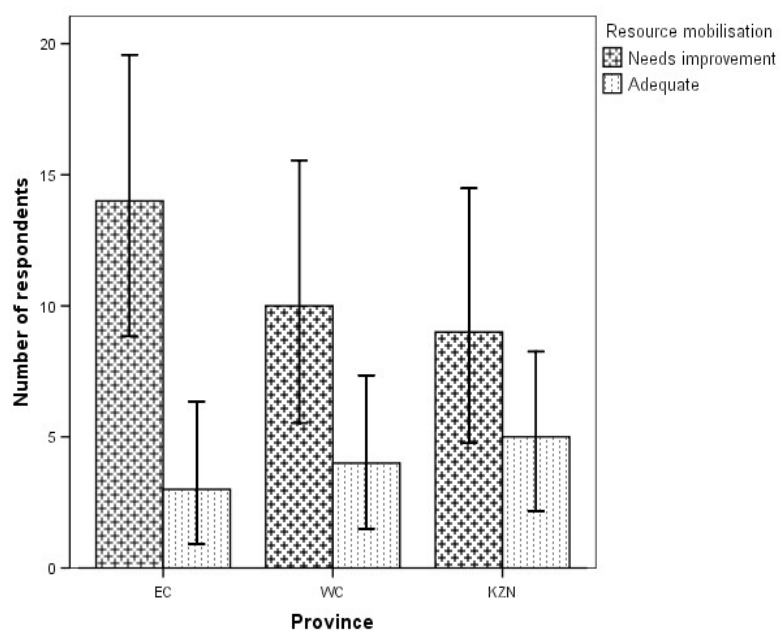

(a)

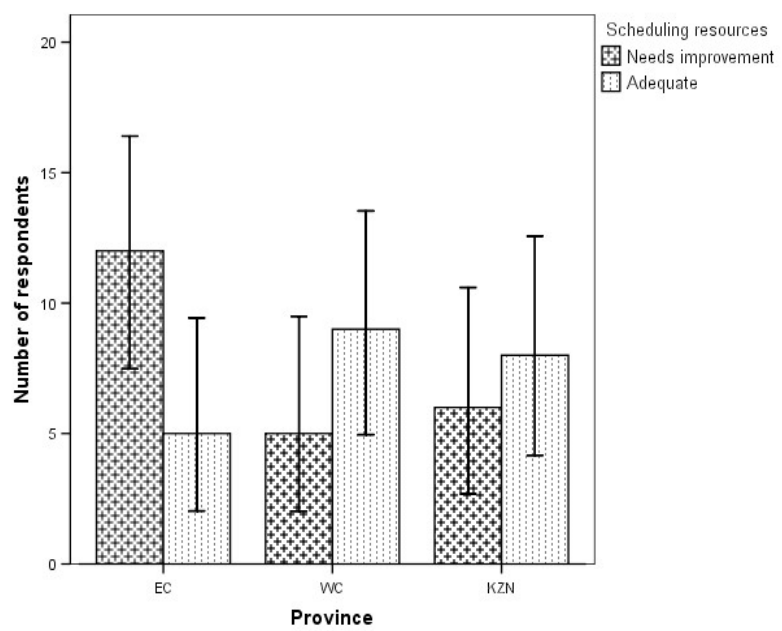

(c)

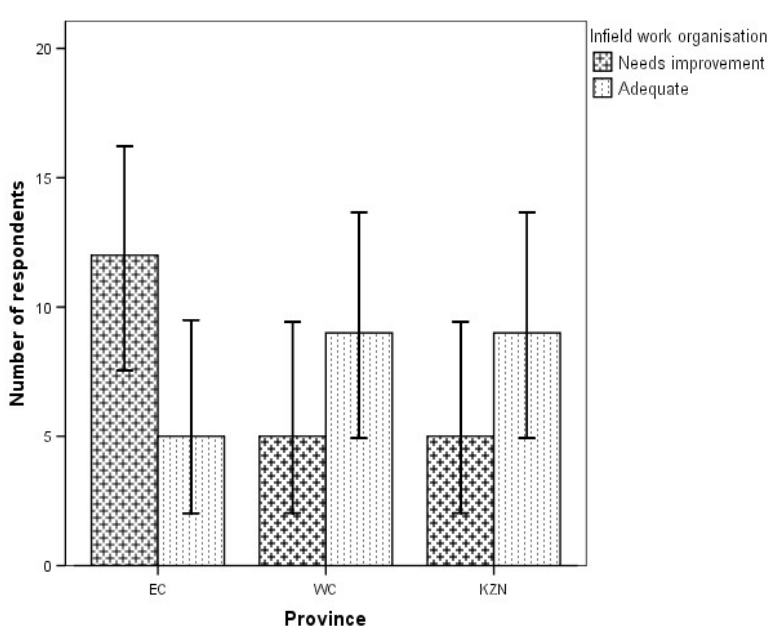

(b)

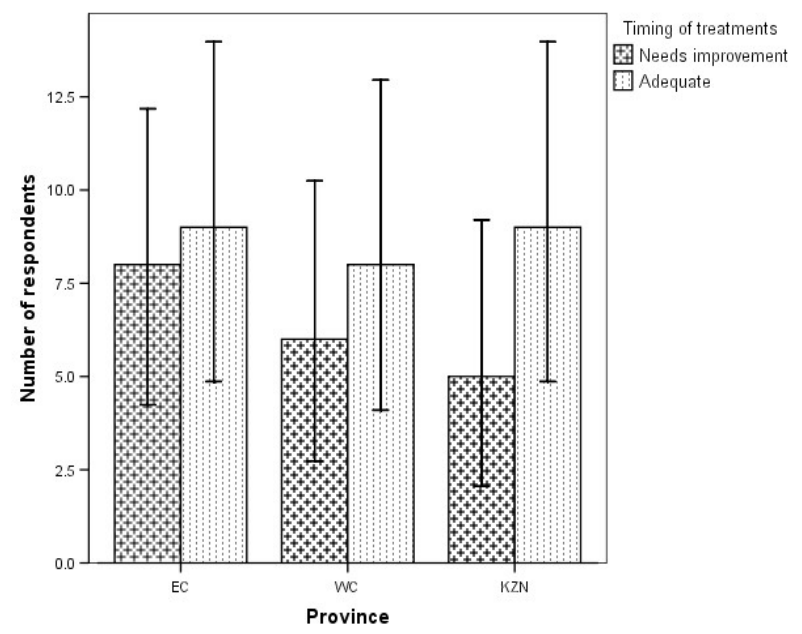

(d)

Fig. 3 Foresters' perceptions of CWFS performance in their role of planning in operational teams in EC, WC and KZN provinces.

EC: Eastern Cape, WC: Western Cape, KZN: KwaZulu-Natal. Error bars show 95\% confidence interval.

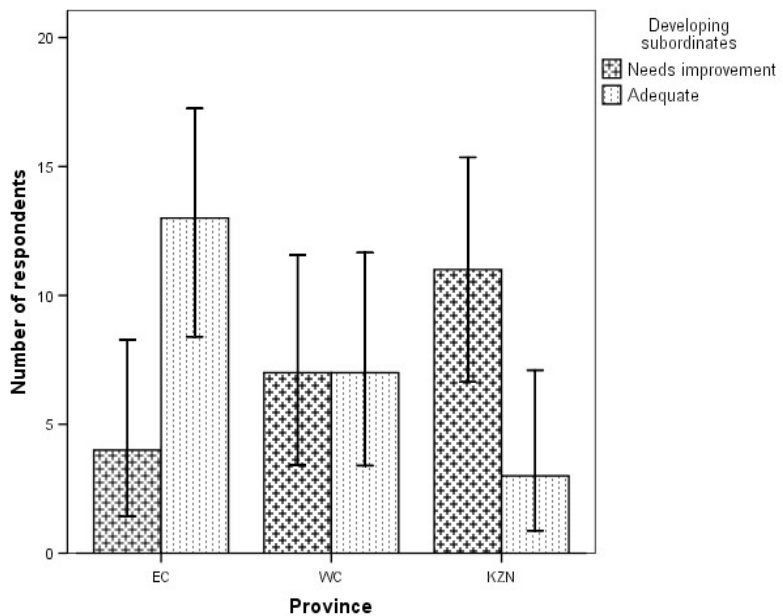

(a)

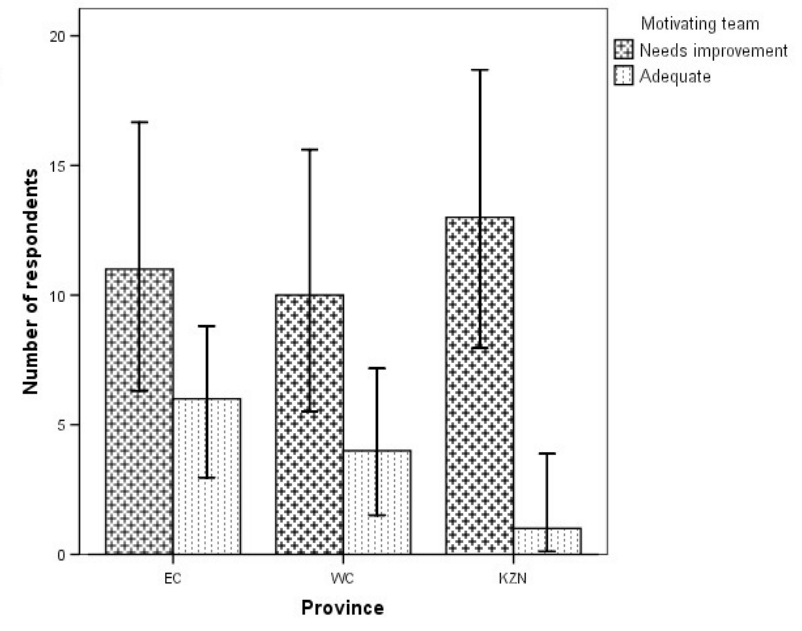

(b) 

Plantation Forest Operations through Forester Perceptions

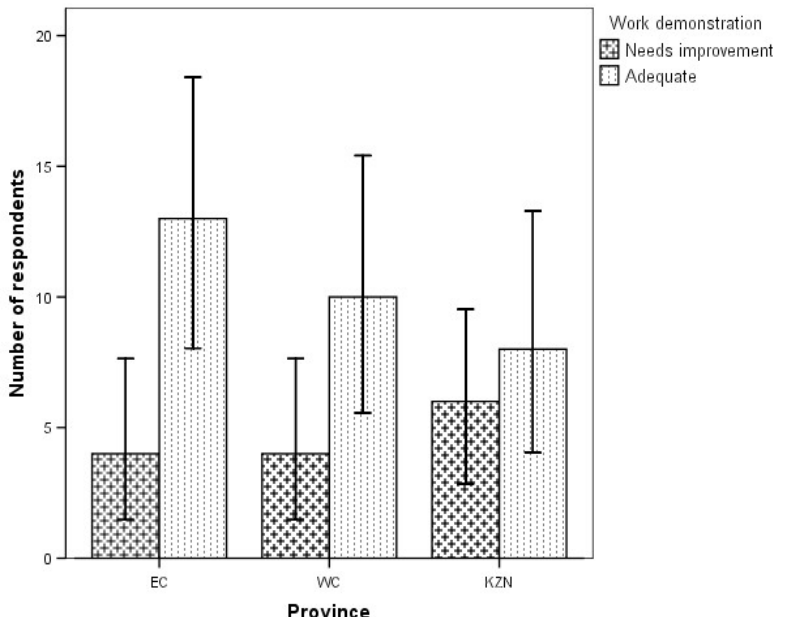

(c)

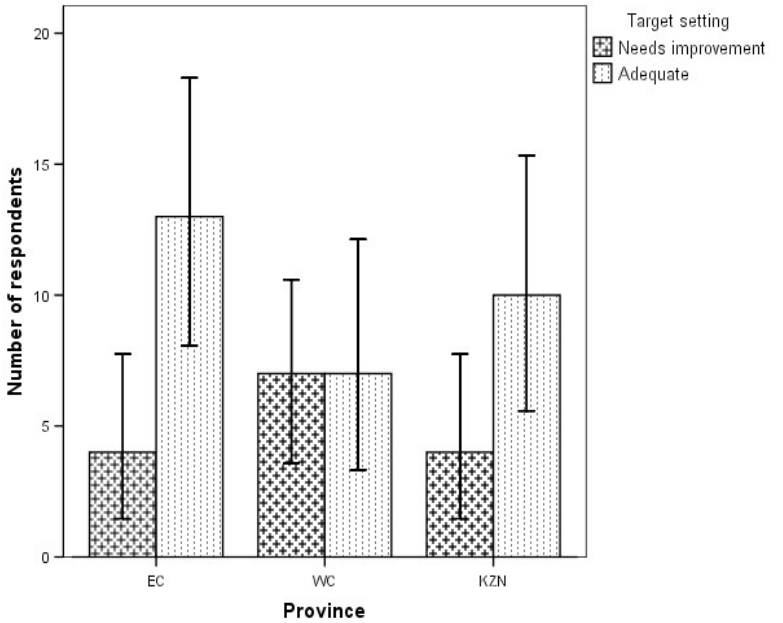

(d)

Fig. 4 Foresters' perceptions of CWFS performance in their role of leading operational teams in EC, WC and KZN provinces.

EC: Eastern Cape, WC: Western Cape, KZN: KwaZulu-Natal. Error bars show 95\% confidence interval.

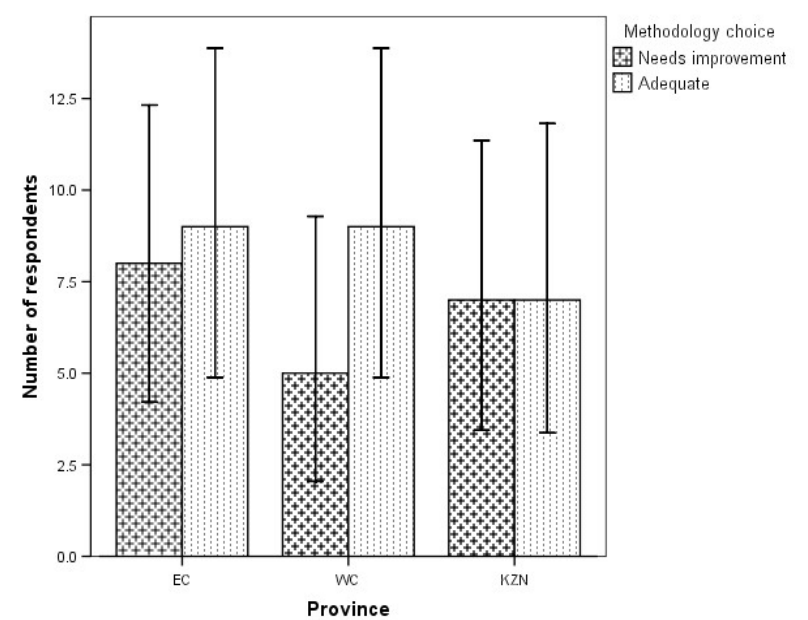

(a)

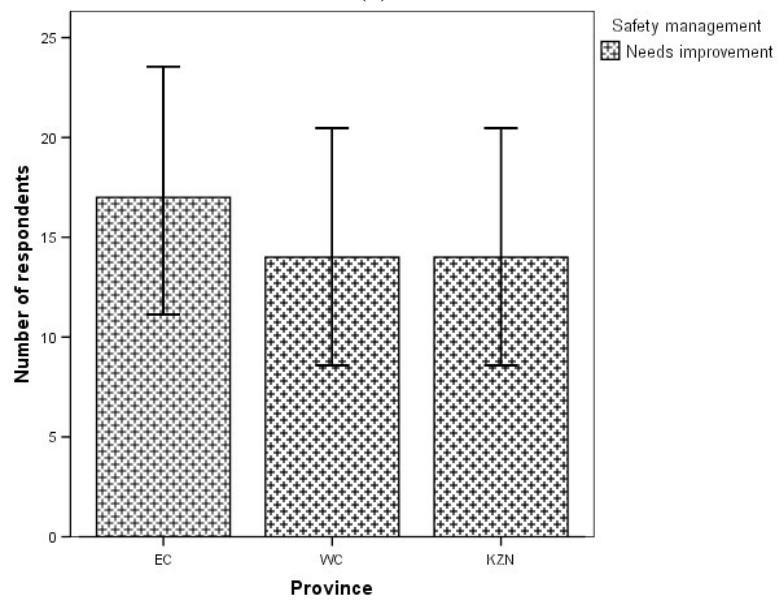

(c)

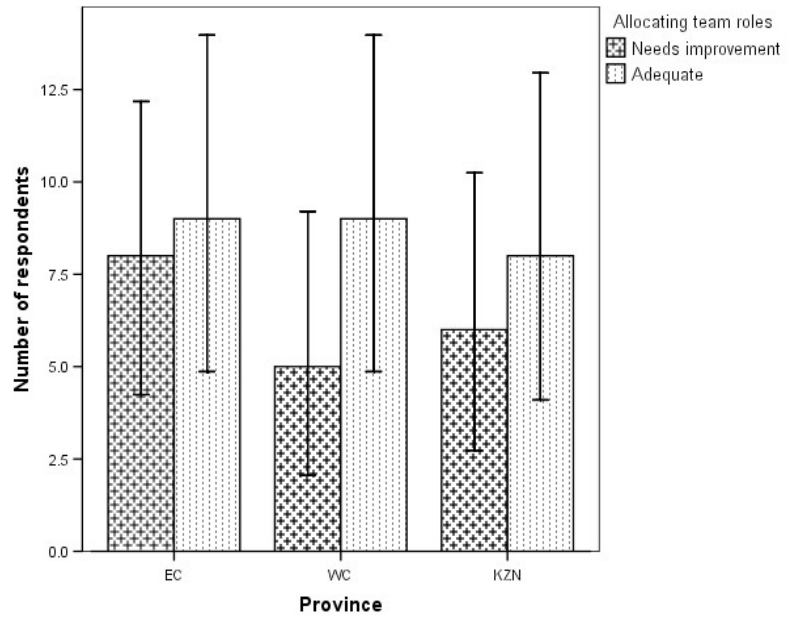

(b)

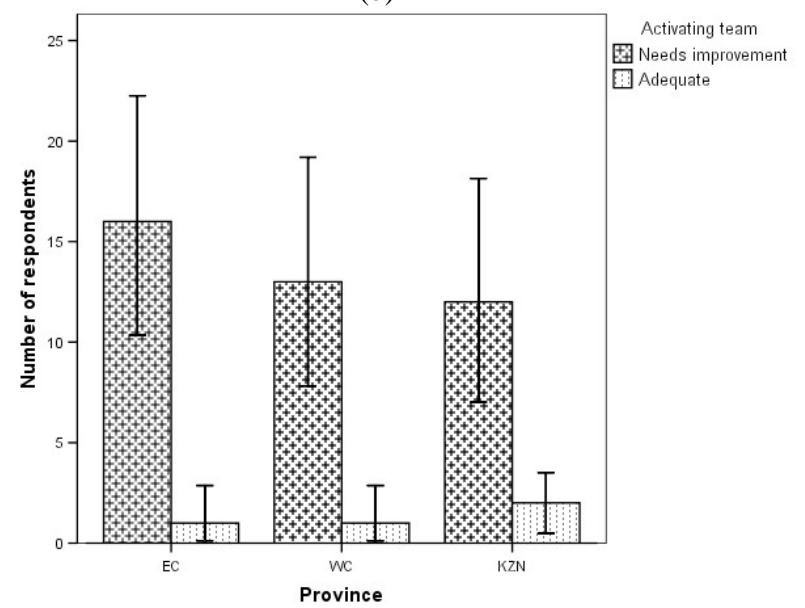

(d)

Fig. 5 Foresters' perceptions of CWFS performance in their role of organizing operational teams in EC, WC and KZN province.

EC: Eastern Cape, WC: Western Cape, KZN: KwaZulu-Natal. Error bars show 95\% confidence interval. 


\subsection{Controlling}

Fig. 6 presents the findings on foresters' perception of CWFS' performance in controlling their operations.

CWFS in all provinces were perceived to be significantly $(P<0.05)$ inadequate in team discipline, while significant $(P<0.05)$ inadequacy in managing costs was confirmed for Eastern Cape and Western Cape provinces. Ability to control team work was also perceived to be significantly $(P<0.05)$ poor in CWFS in KwaZulu-Natal province. Record keeping was, however, considered to be adequate in all provinces.

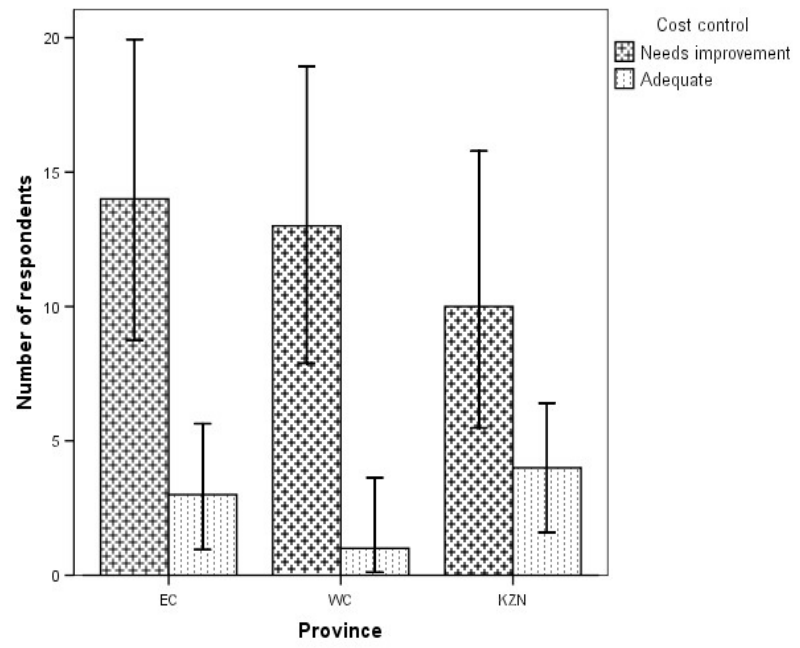

(a)

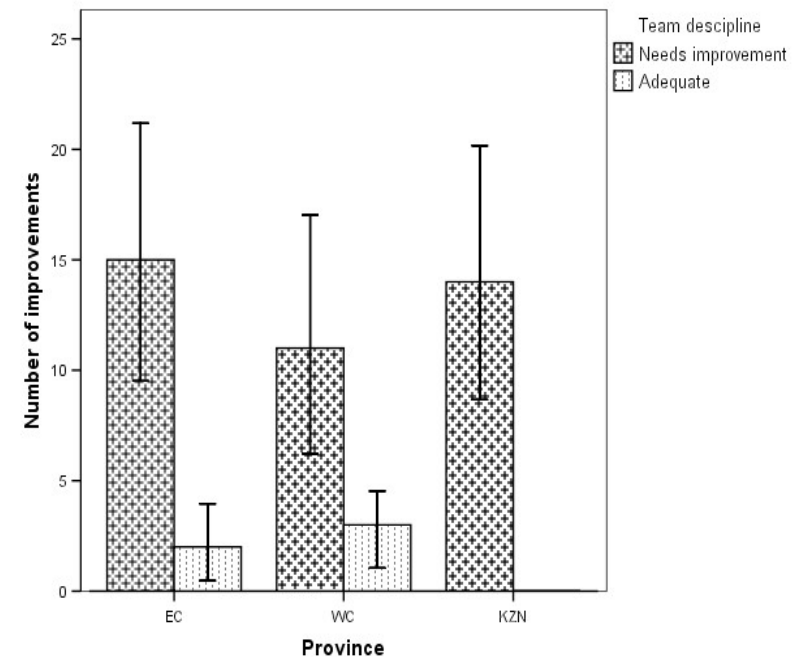

(c)

\subsection{Recommendations by Foresters}

Several important results on suggested interventions, which were offered by respondents (foresters) to improve CWFS, are presented in Fig. 7.

The majority of foresters in all three provinces concurred significantly $(P<0.05)$ that leadership skills of CWFS would benefit from work culture coaching/training rather than training of a technical nature. However, most foresters in all three provinces concurred significantly $(P<0.05)$ that rather than do nothing, both workplace culture and technical training

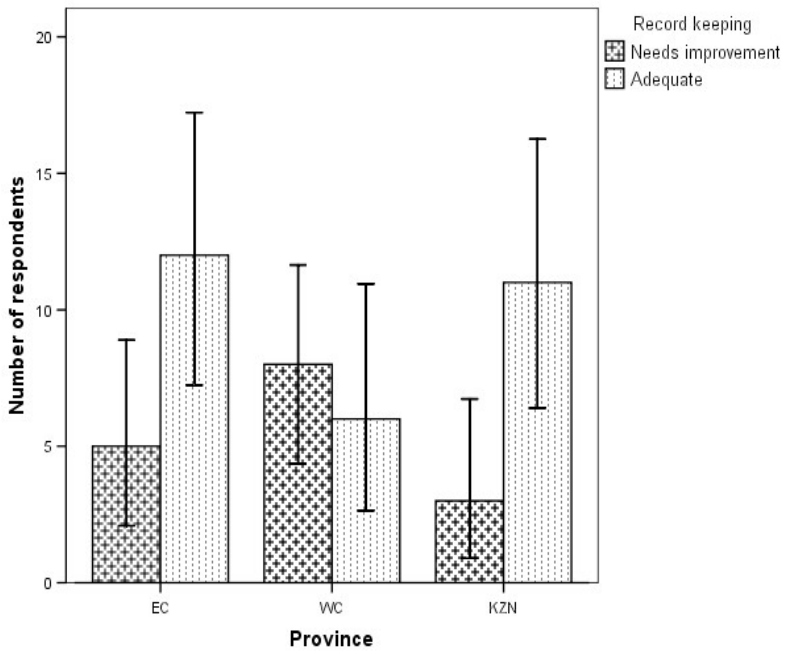

(b)

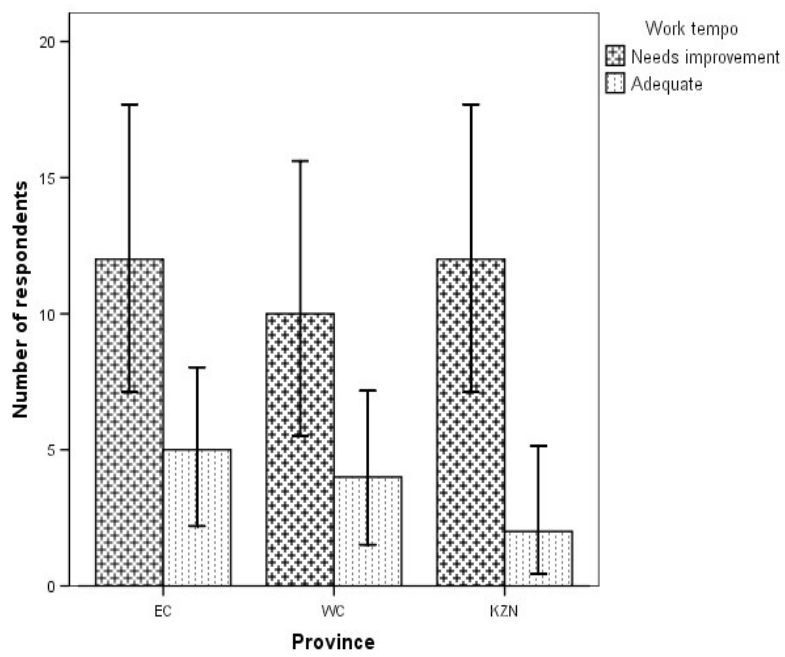

(d)

Fig. 6 Foresters' perceptions of CWFS performance in their role of controlling the efforts of work teams in EC, WC and KZN province.

EC: Eastern Cape, WC: Western Cape, KZN: KwaZulu-Natal. Error bars show 95\% confidence interval. 


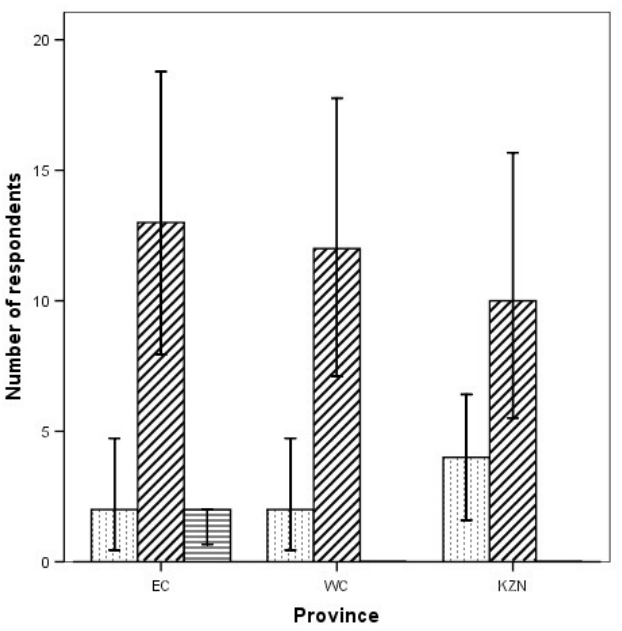

(a)

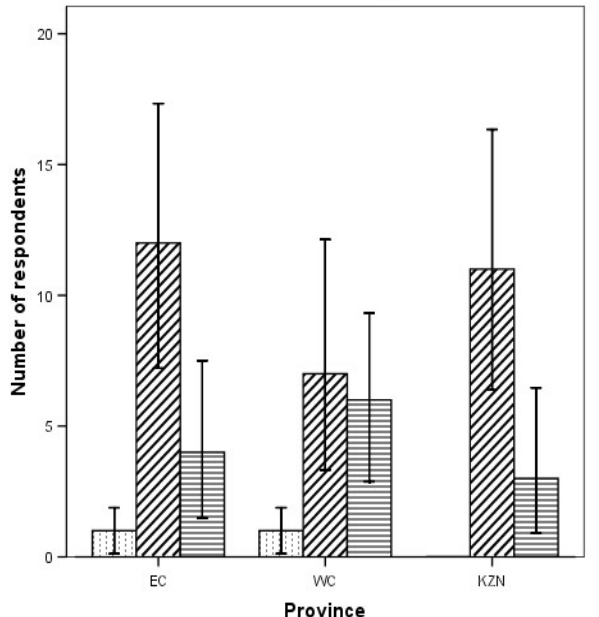

(c)

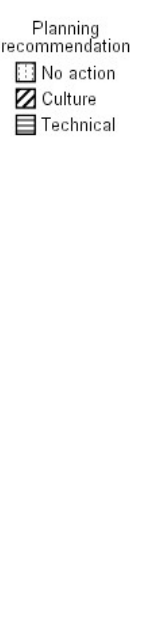

Organising 国 Noulture 買Tecture 㬏

Fig. 7 Foresters' recommendations for improving the performance of CWFS performance in EC, WC and KZN. EC: Eastern Cape, WC: Western Cape, KZN: KwaZulu-Natal. Error bars show 95\% confidence interval. were required to improve the performance of CWFS in controlling operations.

While foresters in the Eastern Cape province considered that planning in CWFS could be improved through workplace culture training, foresters in KwaZulu-Natal FMUs were divided over workplace culture training and taking any action at all. To improve performance in organizing, concurrent workplace culture and technical training were suggested for CWFS in the Eastern Cape and Western Cape provinces, while training in handling workplace culture only, was recommended for CWFS in KwaZulu-Natal.

\section{Discussion}

Inferences from the results of this study fundamentally

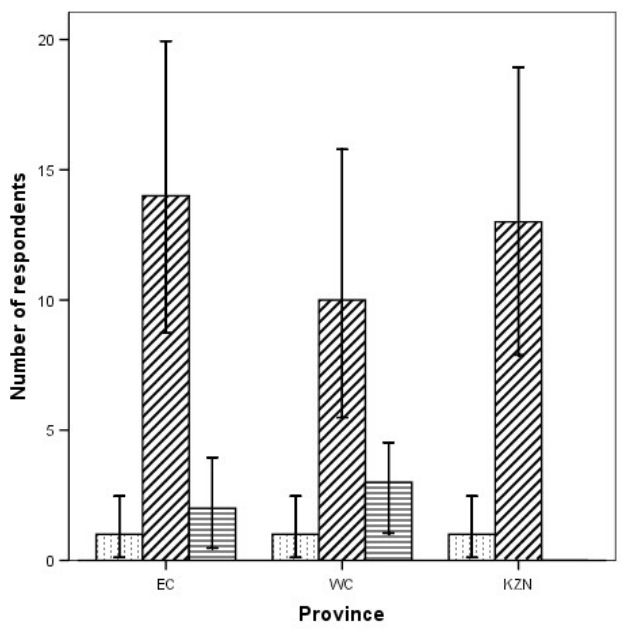

Leading 7 No action $\square$ Culture 目Technical

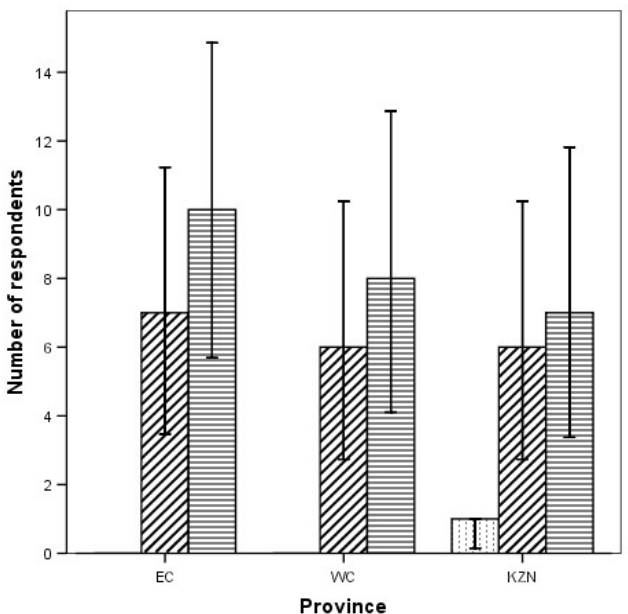

(d)
Controlling No action $\bigotimes$ Culture 目Technica accept that perceptions of foresters on the performance of CWFS, as solicited in the current study, were valid and predictive of the supervisory skills of CWFS in the commercial plantation forests in the Eastern Cape, Western Cape and KwaZulu-Natal provinces. Deductions may, thus, be made in concession of this assumption. The work performance of CWFS may however not be a function of their skills alone; the internal environment of their organizations could confound perceived performance, although the subjects would be expected to possess skills that would permit them to cope. Another important assumption to be conceded is the interpretation of foresters' responses of "needs 
improvement" to directly imply that the performances of CWFS would have been "unsatisfactory" so that the performance needed management intervention, such as vocational training [15], which the foresters are qualified to recommend.

Tellingly, all foresters in the three provinces were unanimous that safety management needed improvement; this is despite verified emphasis on safety as a stated priority in corporate responsibility statements of organizations under which FMUs are managed. In addition, safety is stressed in environmental forest certification schemes [23], under which the FMUs are certified. It follows, therefore, that attention is required in addressing how most CWFS handle safety issues and that capacitation may be provided in the form of training in desirable workplace culture and technical execution of herbicide use. Several service providers are available to offer such training. Besides, line managers (foresters) and chemical suppliers, for safeguard of vested commercial interests, may consider greater participation in developing the skills of CWFS, in particular, and forest herbicide application personnel in general. It may also be valid to interrogate the confidence of foresters in chemical weed management so as to ensure vegetation management efficiency and effectiveness at the FMU level.

Another valid revelation across the three provinces studied was that CWFS performed unsatisfactorily in some aspects related to team organization (Fig. 5) and that the recommendation by foresters (Fig. 7) to consider training the CWFS in workplace culture would be valid. Training in team building and team dynamics could also be incorporated in the recommended training, as this would piggyback the adoption of effective mechanisms to bolster the management of discipline, which was observed to be significantly deficient $(P<0.05)$ in CWFS in all provinces (Fig. 6). It must be borne in mind that organizational culture development cascades from the hierarchy of top management in an organization [24], and because foresters at the MFU level may be peripheral, they would be forced to rely on the commitment of their superiors on making workplace culture support forestry operations. Successful implementation of most recommendations that were advanced in order to improve workplace culture management in CWFS (Fig. 7) would, thus, rely on line management's, i.e., foresters' effective communication with their superiors. This is assuming that the shortfalls in leading, managing team discipline and cost control by CWFS were not due to the foresters not doing enough to entrench the desirable workplace culture. The results of the current study do not, however, provide a basis to speculate on whether the foresters, under the influence of existing organizational culture in their workplaces, would tend to be dissuaded from desirable commitment and adequate execution of their duties [25].

The perceived significantly $(P<0.05)$ poor performance in the areas of leadership (work demonstration, developing subordinates and target-setting) (Fig. 4) together with poor cost control (Fig. 6) in the Eastern Cape province alone entice research interest for the disaggregation of supervisor demographics at FMU level, which the current study's scope lacked. Also of particular interest was the peculiarity of significant $(P<0.05)$ inadequate skills in CWFS for team motivation in KwaZulu-Natal province alone.

\section{Conclusions}

A critical insight into shortfalls in the field supervision of chemical weeding has been offered by the study. Overall, CWFS were adequately prepared to perform in most key result areas of planning and leadership. They faced considerable challenges in functions related to controlling and organizing work. CWFS in the Eastern Cape, Western Cape and KwaZulu-Natal provinces required skills strengthening in cost control, team discipline and safety management. The results show that, 
significantly, based on the view of foresters, there is no panacea for CWFS performance improvement; rather a combination of technical and workplace culture skills training may be imperative. Planned continuous improvement programmes appear to be of sustainable use in this regard.

Future research work requires discriminating the particular sources of patterns that were revealed in this preliminary study. It is suggested that a contact (face-to-face) research approach, preferably soliciting responses separately from both the CWFS and their foresters, should be applied in order to effectively triangulate the responses that are offered.

\section{Acknowledgments}

The authors are greatly indebted to the 60 foresters, who had no hesitation to discuss their work with them, and the students of Fort Cox College of Agriculture and Forestry, who participated in the early stages of the study. Faith Marck who read an earlier draft of the manuscript is also acknowledged.

\section{References}

[1] Little, K. M. 2000. Vegetation Management in Acacia mearnsii: A Synthesis of WRI/ICFR Weeding Trials. Scottsville, South Africa: Institute for Commercial Forestry Research, 25.

[2] Little, K. M., and Rolando, C. A. 2001. "The Impact of Vegetation Control on the Establishment of Pine at Four Sites in the Summer Rainfall Region of South Africa.” Southern African Journal 192 (1): 31-9.

[3] Van Wyk, A., Brink, A., Van Huyssteen, G., and Jansen, J. 2010. Tree Farming Guidelines for Private Growers. South Africa: Sappi Forests.

[4] Godsmark, R. 2010. The South African Forestry and Forest Products Industry 2009. Pietermaritzburg, South Africa: Forestry South Africa.

[5] Louw, J. H., and Scholes, M. 2002. "Forest Site Classification and Evaluation: A South African Perspective.” Forest Ecology and Management 171: 153-68.

[6] Du Toit, B., Smith, C. W., Little, K. M., Boreham, G., and Pallett, R. N. 2010. "Intensive, Site-Specific Silviculture: Manipulating Resource Availability at Establishment for Improved Stand Productivity.” Forest Ecology and Management 259 (9): 1836-45.
[7] Statistics South Africa. 2001. South African Standard Classification of Occupations.

[8] Pieterse, P. J. 2010. "Herbicide Resistance in Weeds-A Threat to Effective Chemical Weed Control in South Africa.” South African Journal of Plant and Soil 27 (1): 66-73.

[9] Little, K. M., Willoughby, I., Wagner, R. G., Adams, P., Frochot, H., Gava, J., Gous, S., Lautenschlager, R. A., Örlander, G., Sankaran, K. V., and Wei, R. P. 2006. "Towards Reduced Herbicide Use in Forest Vegetation Management.” Southern African Forestry Journal 207 (1): 63-79.

[10] Wagner, R. W., Little, K. M., Richardson, B., and McNabb, K. 2006. "The Role of Vegetation Management for Enhancing Productivity of the World's Forests.” Forestry 79 (1): 57-79.

[11] Louw, W. J. A. 2006. "General History of the South African Forest Industry: 2003 to 2006.” Southern African Forestry Journal 208 (1): 79-88.

[12] Chivinge, T., and Sithole, F. 1998. Cost Effective Gum Eradication. A Total Quality Management Project Report, Division of Forestry and Sawmilling, Border Timbers Limited, Mutare, Zimbabwe.

[13] Slappendal, C., Laird, I., Kawachi, I., Marshall, S., and Cryer, C. 1993. "Factors Affecting Work-Related Injury among Forestry Workers: A Review.” Journal of Safety Research 24 (1): 19-32.

[14] Pogue, T. E. 2008. A Sectoral Analysis of Wood, Paper, Pulp Industries in South Africa. Sector Studies Research Project, Institute for Economic Research on Innovation, Tshwane University of Technology, Pretoria.

[15] Steenkamp, J. 2014. "Changes in Forestry Contracting." Wood and Timber Times Southern Africa 39 (3): 28.

[16] Hlengwa, M. 2013. “Time Management for Supervisors.” SA Forestry, December 2013.

[17] Van der Zel, D. W. 1993. "Vocational Forestry Training." In South African Forestry Handbook, edited by Van der Sijde, H. A. Pretoria, South Africa: Southern African Institute of Forestry, 36-7.

[18] Crickmay, A., Hlengwa, M., Olivier, W., and Rusk, G. 2004. "Productivity in the South African Forestry Industry over the Past Decade." Southern African Forestry Journal 201 (1): 1-2.

[19] Koontz, H. 1980. "The Management Theory Jungle Revisited.” Academy of Management Review 5 (2): 175-87.

[20] Mealiea, L., and Baltazar, R. 2005. "A Strategic Guide for Building Effective Teams.” Public Personnel Management 34 (2): 141-59.

[21] Durrheim, K. 2013. “Tutorial 15: One-Way Analysis of Variance.” In Numbers, Hypotheses \& Conclusions: A 

Plantation Forest Operations through Forester Perceptions

Course in Statistics for the Social Sciences, edited by Tredoux, C., and Durrheim, K. Cape Town, South Africa: UCT Press, 271-88.

[22] SPSS Inc.. 2005. SPSS Statistics for Windows. Version 14.0. Chicago, United States of America: SPSS Inc..

[23] Frost, B., Mayers, J., and Roberts, S. 2003. Growing Credibility: Impact of Certification on Forests and People in South Africa. London: International Institute for Environment and Development.

[24] Sun, S. 2008. "Organizational Culture and Its Themes." International Journal of Business and Management 3 (12): 137-41.

[25] Manetje, O., and Martins, N. 2009. “The Relationship between Organizational Culture and Organizational Commitment.” Southern African Business Review 13 (1): 87-111. 